\title{
Tractament d'idees alternatives de física en educació secundària
}

\author{
Àngel Luis Torres Climent (angeltorresfq@yahoo.es) IES Joanot Martorell d'Elx (Alacant)
}

El present treball mostra una proposta metodològica per canviar certes idees alternatives de la Física de l'Educació Secundària, per idees científiques. La proposta persegueix arribar al canvi conceptual i metodològic a través del plantejament de situacions d'indagació, discussió i comunicació dels alumnes, ocupant un paper fonamental del procés, la contrastació experimental de les hipòtesis.

Paraules clau: Idees alternatives de Física, canvi conceptual, canvi metodològic, experiments senzills a l'aula.

The present work shows a methodological propose to change some alternative ideas related with Physics in high school education, for scientific ideas. That propose tries to get a conceptual and methodological change by proposing inquiry situations, students' discussion and communication, in which experimental contrast of the hypotheses occupies a fundamental role in the process.

Paraules clau: physics alternative idees, conceptual change, methodological change, simple experiments in the classroom.

\section{INTRODUCCIÓ}

El professorat de Física coneix bé, que gran part dels seus alumnes diferencien entre la "física de la pissarra", que els permet aprovar els seus exàmens, i la "física real" que apliquen per resoldre les situacions que se'ls plantegen en la seva vida quotidiana. Si preguntéssim a un alumne: quin objecte arribarà abans al sòl, un objecte pesat 0 un lleuger? Els alumnes no tenen dubtes: el més pesat. A les respostes contradictòries amb els coneixements científics que se solen donar de manera ràpida $i$ segura, es repeteixen insistentment $i$ que les cometen gran nombre d'alumnes de diferents llocs, les hi denominen errors conceptuals i les idees que porten a cometre'ls, concepcions alternatives (Carrascosa, 2005).

\section{EXPERIÈNCIA}

L'objectiu d'aquesta experiència va ser iniciar una metodologia que abordés el tractament d'idees alternatives habituals en la Física de l'Educació Secundària. L'experiència va comprendre l'actuació en dues fases: la primera es va desenvolupar durant el curs 2013/14 amb alumnes de Física de $2^{n}$ de Batxillerat i va comprendre les següents etapes:

- Elecció d'idees alternatives habituals en l'alumnat de Secundària i Batxillerat. Per a aquest apartat es van consultar interessants treballs, com el de Carrascosa i Gil-Pérez (1992) i Hernández Villalobos (2010).

- Estudi de cada problema i elaboració de la pregunta que permet aflorar les idees alternatives.

- Elaboració d'un guió pel vídeo que respon la pregunta mitjançant la contrastació experimental.

- Creació del blog que presenta els materials en la xarxa amb format actual i amb una disposició clara i senzilla tal com s'ha fet en altres treballs 
com els de Faus (2007) i Gilart (2008): http://lasmentirasdelafisica.blogspot.com.es/

La segona fase es va desenvolupar durant el curs 2014/15 amb 28 alumnes de Física i Química de $4^{t} d^{\prime} E S O$ i en ella es va implementar a l'aula el contingut creat en la fase anterior. La seqüència seguida en aquesta fase va ser la següent:

- El professor realitza un plantejament de la qüestió al grup, prèviament dividit en subgrups de 45 alumnes per facilitar el debat i la posada en comú de les hipòtesis.

- Posada en comú de les hipòtesis amb confrontació de les mateixes, sota la dinamització del professor, que no facilita la "resposta correcta".

- Visionat del vídeo i de l'explicació que ofereix el cos de coneixement científic.

- Plantejament d'un problema "diferent" (per a l'alumne) que no obstant això es pot explicar amb el mateix cos de coneixement (per exemple les lleis de la dinàmica) i que per això creem pot facilitar el canvi conceptual en l'alumne.

S'ha d'aclarir que aquesta experiència no exclou en absolut, la possibilitat que els alumnes desenvolupin els experiments de forma real en el laboratori, únicament tracta d'aprofitar els avantatges d'utilitzar experiments gravats com poden ser que requereixen d'un temps molt inferior al d'una execució real, s'assegura el resultat o es permet repetir el visionat les vegades que sigui necessari. Algunes de les qüestioni plantejades van ser les següents

\section{Alguns exemples de qüestions plan- tejades}

Pesa la bola?: En una balança hi ha un got amb aigua. Si introduïm en l'aigua una bola penjada d'un fil sense que arribi a tocar el fons del got (Figura 1). a) La balança assenyala més pes que abans. b) La balança assenyala el mateix pes que abans. c) La balança assenyala menys pes que abans.

La majoria d'alumnes (65\%) responen que la balança no notarà augment de pes perquè la bola no toca el platet. Segons la tercera llei de la dinàmica, l'empenta del líquid sobre el cos, porta associada una força igual i de sentit contrari sobre l'aigua, que en la situació descrita fa que la balança es desviï indicant un augment de la força exercida sobre el plat. Per tant, la balança marcarà major pes com més gran sigui el pes de l'aigua desplaçada per la bola.

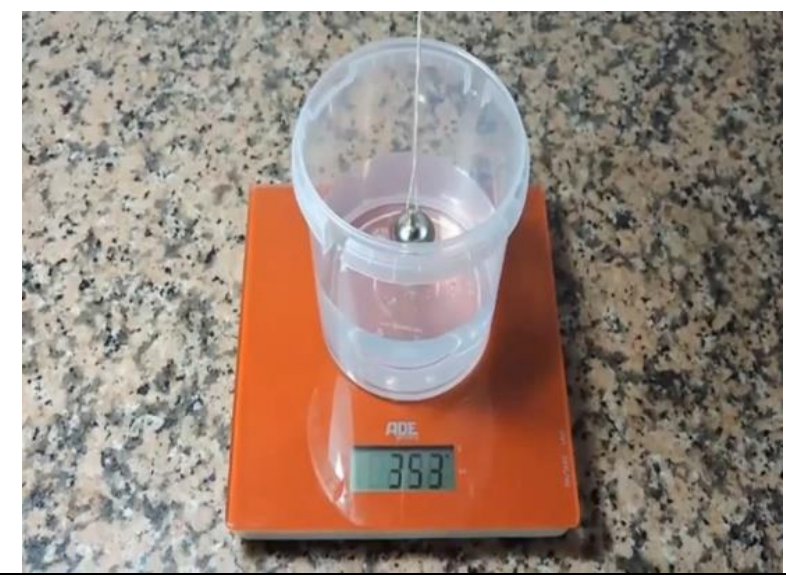

Figura 1. Dispositiu utilitzat per plantejar la qüestió: Pesa la bola?

Què cau més ràpid?: Què arribarà abans al sòl, un cos o un altre amb el doble de massa, deixats anar tots dos des de la mateixa altura? (Figura 2). La majoria d'alumnes (85\%) pensa que arribarà abans al sòl, el cos que té major pes. La llei fonamental de la dinàmica estableix que tots els cossos sotmesos, només per força pes, cauran amb la mateixa acceleració, $g$, independentment de la seva massa. El resultat que mostra el vídeo, no deixa lloc a dubtes. No obstant això es podria plantejar que, per exemple un paracaigudista, triga més a arribar al sòl que un objecte de la seva mateixa massa. La llei fonamental de la dinàmica proporciona de nou la resposta, ja que si la superfície del cos és gran, la força de fricció no és menyspreable i l'acceleració de caiguda, a, serà inferior a l'acceleració de la gravetat, $g$.

$$
\mathrm{m} \cdot \mathrm{g}-\mathrm{F}_{\text {fregament }}=\mathrm{m} \cdot \mathrm{a} ; \mathrm{a}<\mathrm{g}
$$

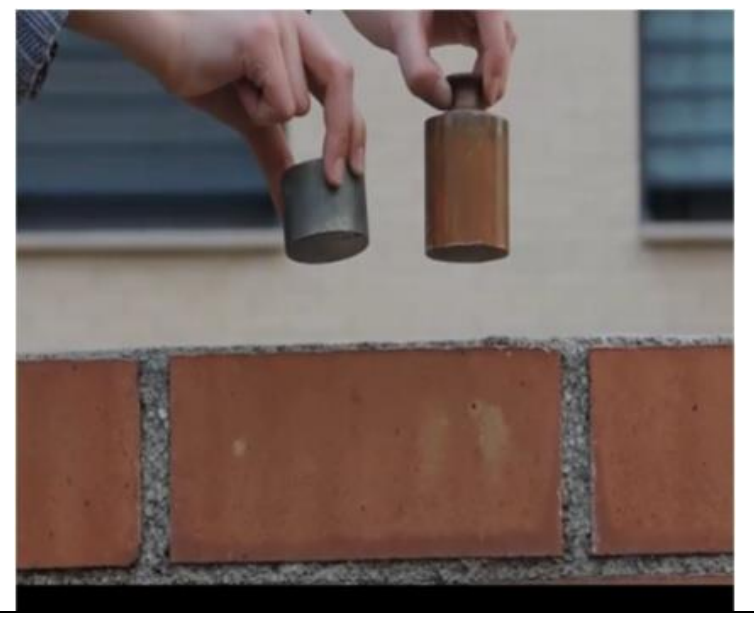

Figura 2. Comprovació experimental: Què cau més ràpid? 
Cambrer imprudent?: Què li passarà als plats i coberts de la taula, si tiréssim de les estovalles? (Figura 3).

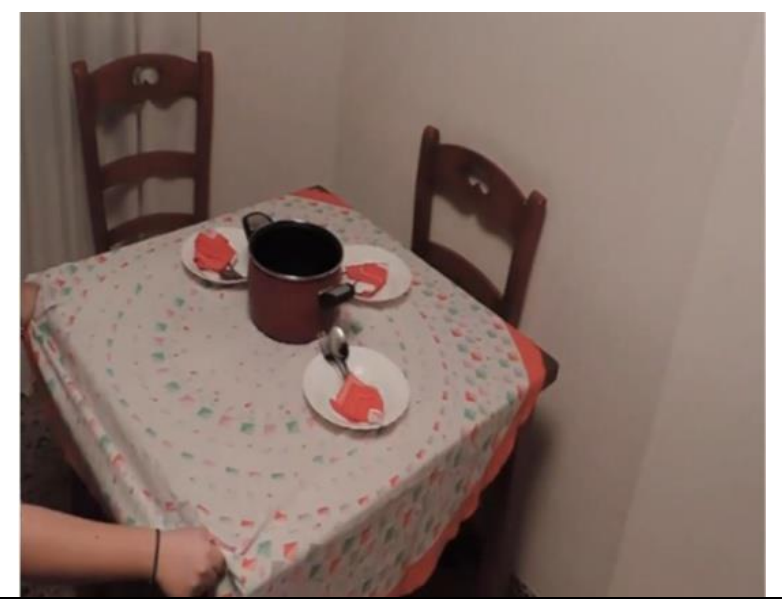

Figura 3. Demostració de l'experiència "Cambrer imprudent"

La majoria dels alumnes (55\%) demanaran que no es faci aquesta prova perquè plats i coberts acabarien pels sòls. Per aconseguir que els objectes no es moguin, és necessari que el moviment de les estovalles sigui molt ràpid, doncs d'aquesta forma la força de fregament actuarà molt poc temps sobre gots i coberts, acudint de nou al principi fonamental de la dinàmica:

$$
\begin{gathered}
F_{\text {fregament }}=\mathrm{m} \cdot \mathrm{a} \\
\mathrm{F}_{\text {fregament }} \cdot \Delta \mathrm{t}=\mathrm{m} \cdot \Delta \mathrm{v} ; \mathrm{Si} \Delta \mathrm{t} \rightarrow 0 \text {, llavors } \Delta \mathrm{v}
\end{gathered}
$$

Per on anirà?: Una vegada llançada la bola en el plat de la figura 4, quina trajectòria seguirà quan ho abandoni?

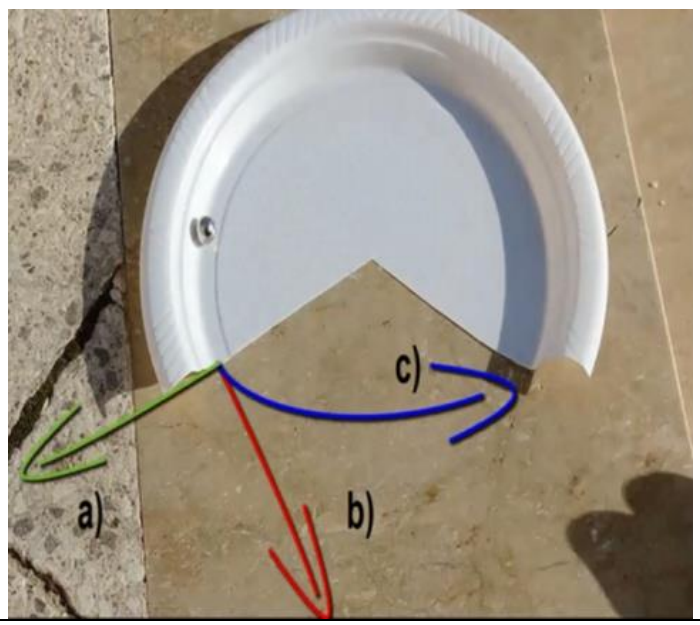

Figura 4. Quina trajectòria seguirà la bola?
Aquesta és una activitat inclosa en el llibre de Vidal i col. (2008) que ens va proporcionar com a respostes majoritàries la b) i la c) (60 \%), encara que en general els alumnes no les saben justificar. Si no hi ha plat no hi ha força centrípeta que "guiii" al cos i si la força total que actua sobre un cos és nul-la, segons la primera llei de la dinàmica, el cos es trobarà en repòs o es mourà a rapidesa constant en línia recta. Però quina línia recta? Aquest, és un excel-lent moment per acudir al caràcter vectorial de moltes magnituds físiques i recordar que la direcció del vector velocitat instantània en cada punt de la trajectòria té la direcció de la recta tangent en aquest punt.

Ens escalfen els abrics?: Aquesta és una qüestió ja plantejada pel famós físic rus Perelmán (1975) i proposta amb variacions en Lozano i Solbes (2014). Els alumnes donen una resposta afirmativa pràcticament unànime i per això es pot sol-licitar que es respongui a la qüestió següent: Es tenen dos gots trets del frigorífic amb aigua a la mateixa temperatura $\left(5,7^{\circ} \mathrm{C}\right)$. En deixar un got exposat a l'ambient $i$ un altre envoltat per una manta, s'escalfarà l'aigua del got abrigallat per la manta? (Figura 5).

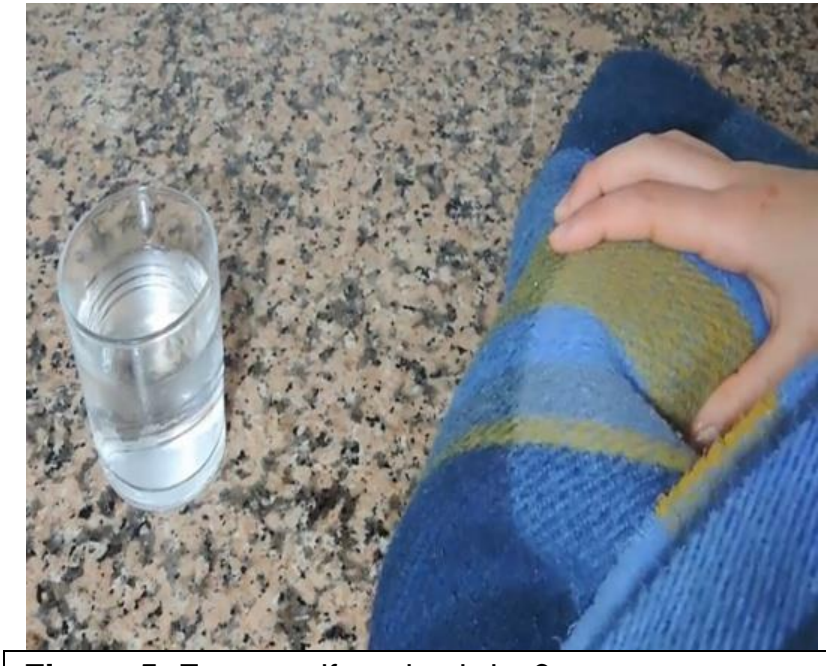

Figura 5. Ens escalfen els abrics?:

Passats uns minuts, la temperatura del got sense tapar és $10,5^{\circ} \mathrm{C}$ i la del got abrigat és de $7^{\circ} \mathrm{C}$, menor que la de l'aigua no abrigada!! La teoria científica sobre la calor proposa que la calor es transfereix espontàniament des del cos a major temperatura, fins al qual està a menor temperatura. El que ha ocorregut és que l'aigua sense tapar ha rebut calor de l'ambient, mentre que l'abrigada no ha rebut tanta calor de l'ambient, perquè la manta és un material aïllant, és a dir no permet que la calor flueixi fàcilment al seu través, però la manta en 
si mateixa no dóna calor. L'abric realment no escalfa, si s'entén per "escalfar" donar calor.

Ens enganyen les lents?: Pot un mitjà transparent, diferent a l'aire, fer-nos veure imatges diferents dels objectes? El llibre de Vidal i col. (2008) ens planteja aquesta curiosa experiència. Entre els alumnes hi ha una part important $(40 \%)$ que no creuen que la imatge pugui ser diferent a l'objecte que la produeix. En posar l'ampolla "vertical" damunt de la fletxa de meitat superior blava i inferior blanca, aquesta canvia de sentit. Quan mirem la fletxa a través de l'ampolla "horitzontal", la meitat blava de la fletxa s'observa sota i la meitat blanca a dalt (Figura 6).

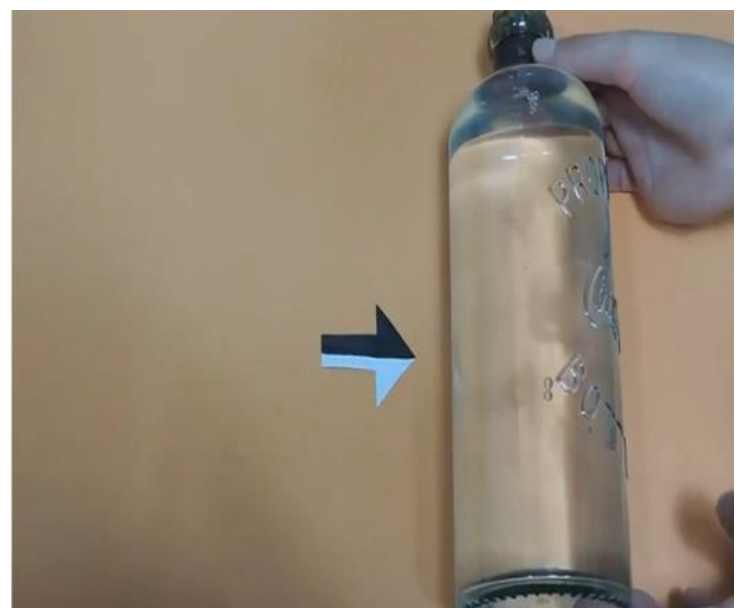

Figura 6. Ens enganyen les lents?

Per a l'alumnat de Secundària, probablement bastaria amb comprendre que els objectes són vistos, gràcies a la llum que reflecteixen i que la imatge de l'objecte es veu en el lloc on aquests raigs es tallen o no es tallen les seves prolongacions. Cada vegada que la llum canvia de mitjà (aire-aigua i aigua-aire) es desvia (refracta) produint-se les imatges observades.

Groc més blau, verd?: Si barregem pintura groga més blava, s'obté pintura verda. Obtindrem llum verda en unir llum groga i llum blava? Tots els alumnes responen de forma afirmativa, però en superposar llum groga i llum blava de la mateixa intensitat, s'obté llum blanca!! No és necessari tot l'espectre per aconseguir llum blanca sinó que pot ser suficient barrejar tres llums de colors vermell, verd i blau (colors anomenats primaris) o dues llums de les denominades complementàries (groc, magenta i cian) (Figura 7).

En sumar llums de diferents colors ens anem apropant a la llum blanca (mescla additiva), no obs- tant això un pigment, com per exemple el groc, absorbeix la llum blava i deixa passar les altres (verda i vermella que veiem groga) de tal forma que en anar sumant pigments de diferents colors anem restant llum fins a arribar al negre (mescla sostractiva).

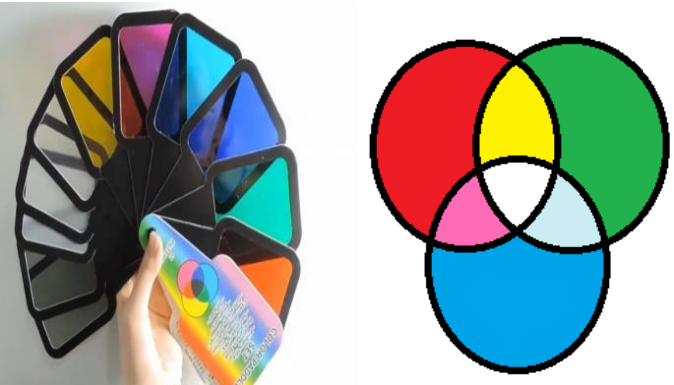

Figura 7. Groc més blau, verd?

\section{CONCLUSIONS}

El treball ens ha permès iniciar una metodologia que creem pot ser útil en el tractament de les idees prèvies alternatives de la física en Secundària. S'ofereix un espai blog amb una oferta de contingut, que sens dubte haurem d'ampliar-la en el futur. S'ha corroborat que l'acceptació de l'experiència ha sigut satisfactòria (un $94 \%$ dels alumnes l'aprova) i observem que ha propiciat l'augment de l'interès, arribant fins i tot a establir-se certa competició entre els alumnes per plantejar la hipòtesi que finalment resultés acceptada. Creem que la metodologia seguida provoca canvi conceptual en la major part de l'alumnat (així ho reconeix un $75 \%$ dels alumnes), encara que creem que respecte a la permanència d'aquest canvi en el temps, s'ha d'imposar la cautela i sens dubte haurem d'ampliar l'experiència en el futur, per poder extreure resultats significatius.

\section{AGRAIIMENTS}

A les alumnes Verónica Narro Ruiz, Quiong Quiong Sun i María Blasco Zaballos de $2^{\text {n }}$ de Batxillerat de I'Institut Joanot Martorell d'Elx, perquè sense la seua il-lusió, tenacitat, capacitat i clara vocació científica, no hauria segut possible aquest treball.

\section{BIBLIOGRAFÍA}

CARRASCOSA, JAIME I GIL-PÉREZ, DANIEL. (1992). Concepciones alternativas en mecánica. Enseñanza de las Ciencias, 10 (3), 315-328.

CARRASCOSA, JAIME. (2005). El problema de las concepciones alternativas en la actualidad (parte I). Análisis sobre las causas que la originan 
y/o mantienen. [Article en línia] Revista Eureka sobre Enseñanza y divulgación de las Ciencias, 2 (2), 183-208.

FAUS, JOAN A. (2007). L'aula de noves tecnologies per a les ciències: aplicacions a l'ESO. Ciències, 6, 2-5.

GILART, M. CARME. (2008). Experiments: tan senzills i tan exemplificadors. Ciències, 10, 2427.

HERNÁNDEZ VILLALOBOS, LORENZO. (2010). 40 Cuestiones para saber si alguien sabe física sin cálculos: http://www.cienciaonline.com/2010/10/28/40cuestiones-para-saber-si-alguien-sabe-fisicasin-calculos/

LOZANO, ÓSCAR I SOLBES, JORDI. (2014). 85 experimentos de física cotidiana. Vol. 305. Barcelona: Graó.

PERELMAN, YAKOV. (1975). Física recreativa. Moscú: Mir.

VIDAL, MARÍA DEL CARMEN; DE PRADA, FERNANDO; SANZ, PABLO I GARCÍA-MOLINA, RAFAEL. (2008) Física y Química $4^{\circ}$ eso. Proyecto La casa del saber. Madrid: Santillana. 